\title{
The Influence of Decentralized Wind Power on the Characteristics of Distribution Network
}

\author{
Ruomeng Jiang ${ }^{1,2, *}$ \\ 1.State Grid Energy Research Institute Co., Ltd., 102209 Beijing, China \\ 2.State Grid Talents Exchange and Service Center Company Limited (State Grid Talents Evaluation Center), 100053 \\ Beijing, China
}

\begin{abstract}
This paper expounds the influence of decentralized wind power on the characteristics of distribution network. Through analysis, it can be concluded that after installing an appropriate amount of decentralized wind power, the voltage level of load bus can be improved. The power flow distribution will be changed, and the network loss of the power grid will be reduced. The decentralized wind power has also brought about negative impacts, such as voltage flicker and harmonics, the impact on the scope and direction of protection of relay protection, and greater uncertainty in the planning and operation of regional power grid. The analysis above provides some theoretical guidance for the large-scale development of decentralized wind power in the future.
\end{abstract}

\section{Introduction}

As the energy crisis, climate warming and environmental pollution become more serious, the development of green and renewable energy has become a major strategy for the sustainable development of all countries in the world. Under this background, the wind power installed capacity in China increased rapidly, the integration of large-scale wind power into the UHV transmission grid has become the mainstream form of wind power grid connection. However, the problems of wind power transmission and grid security caused by large-scale wind power development have become increasingly serious. Therefore, the development of decentralized wind power in accordance with local conditions can not only alleviate the shortage of electricity, but also save energy such as coal and petroleum, thus playing a good role in environmental protection ${ }^{[1,2]}$.

There have been relevant studies on the issue of decentralized wind power at home and abroad. There are many researches on the integration of distributed power sources into the distribution network, but there are relatively few studies on the impact of decentralized wind power integration into the distribution network. On the one hand, due to the inherent defects of decentralized wind power, such as uncertainty and volatility, it will affect the system's network loss, voltage level, and shortcircuit current ${ }^{[3,4]}$. Literature [5] discusses the future development trend of wind power in China, and the impact of decentralized wind power on the distribution network in different scenarios. Literature [6] studies the impact of decentralized wind power on the voltage fluctuations of the regional distribution network. Literature [7] discusses the influence of decentralized wind power on the loss of the distribution network. However, the research on decentralized planning at home and abroad is at the initial stage and the theory is not mature. Therefore, it is necessary to conduct in-depth research on decentralized wind power.

This paper mainly describes the impact of distributed wind power on the characteristics of the distribution network, including voltage level, power quality, power flow distribution, relay protection, and grid planning. Finally, this article summarizes and prospects for future work.

\section{The influence of decentralized wind power on characteristics of distribution network}

\subsection{The influence of decentralized wind power on voltage level}

The traditional distribution network is generally radial. Under steady-state operation, the voltage along the feeder flow direction will gradually decrease. After the wind power is connected, the voltage at each load node along the feeder is raised due to the reactive power output of the wind power. How much the voltage is raised is related to the location of the connected wind power and the total capacity.

The load voltage is compared and analyzed before and after the connection of decentralized wind power. Suppose the active and reactive power of the load are $P_{\text {load }}$ and $Q_{\text {load, }}$, the active and reactive power loss of the line are $P_{\text {loss }}$ and $Q_{\text {loss }}$ respectively. The voltage of the collection point is $U_{\mathrm{s}} . R$ and $X$ are the resistance and reactance of the line from the load to the collection point respectively.

\footnotetext{
${ }^{*}$ Corresponding author: renleijrm@163.com
} 
The vertical and horizontal components of voltage drop before the decentralized wind power is connected are:

$$
\begin{aligned}
& \Delta U_{L 1}=\frac{\left(P_{\text {load }}+P_{\text {loss }}\right) R+\left(Q_{\text {load }}+Q_{\text {loss }}\right) X}{U_{S}} \\
& \delta U_{L 1}=\frac{\left(P_{\text {load }}+P_{\text {loss }}\right) X-\left(Q_{\text {load }}+Q_{\text {loss }}\right) R}{U_{S}}
\end{aligned}
$$

The voltage of the load before the distributed wind power is connected is:

$$
U_{L 1}=\sqrt{\left(U_{S}-\Delta U_{L 1}\right)^{2}+\left(\delta U_{L 1}\right)^{2}}
$$

Suppose the active and reactive power output of the distributed wind power are $P_{\mathrm{G}}, Q_{\mathrm{G}}$, respectively. The vertical and horizontal components of voltage drop after the decentralized wind power is connected are:

$$
\begin{aligned}
& \Delta U_{L 2}=\frac{\left(P_{\text {load }}+P_{\text {loss }}-P_{G}\right) R+\left(Q_{\text {load }}+Q_{\text {loss }}-Q_{G}\right) X}{U_{S}} \\
& \delta U_{L 2}=\frac{\left(P_{\text {load }}+P_{\text {loss }}-P_{G}\right) X-\left(Q_{\text {load }}+Q_{\text {loss }}-Q_{G}\right) R}{U_{S}}
\end{aligned}
$$

The voltage of the load after the distributed wind power are connected is $U_{\mathrm{L} 2}$.

$$
U_{L 2}=\sqrt{\left(U_{S}-\Delta U_{L 2}\right)^{2}+\left(\delta U_{L 2}\right)^{2}}
$$

From the above equations (1)-(6), it can be seen that the electric energy is transmitted through the line, especially on the heavy load, a large voltage drop is generated on the distribution line with long lines, so that the terminal voltage of the system is lower and cannot meet the power supply requirements. Comparing analysis (3) and (6), it can be concluded that after installing an appropriate amount of distributed wind power, the power transmitted on the line is reduced, the line voltage drop is reduced, and the voltage level of the load bus is improved.

\subsection{The influence of decentralized wind power on power quality}

\subsubsection{Voltage fluctuation and flicker caused by decentralized wind power}

(1) Causes of voltage fluctuation and flicker

The fundamental cause of voltage fluctuation and flicker caused by distributed wind power is the fluctuation of the output power of grid-connected wind turbines. The output power of wind turbines fluctuates continuously between the actual power and the rated power as the wind conditions change. In addition, in the process of unit switching operation, the switching operation will cause power fluctuations, which will cause voltage fluctuations and flicker of wind turbines ${ }^{\left[{ }^{[8]}\right.}$.

(2) Calculation of voltage flicker

According to the IEC61400-21 standard Gridconnected Wind Turbine Power Quality Test and Evaluation", the flicker value of wind turbines or wind farms in continuous operation and switching operation can be calculated ${ }^{[9]}$. a. Continuous operation

The total flicker during continuous operation of multiple units in a wind farm can be calculated from the formula (7):

$$
P_{s t}=\frac{1}{S_{k}} \sqrt{\sum_{i=1}^{N_{w t}}\left(c_{i}\left(\psi_{k}, v_{a}\right) * S_{n, i}\right)^{2}}
$$

Among them, $S_{k}$ is the short-circuit capacity of the common connection point; $c_{i}$ refers to the flicker coefficient of a single wind turbine; $S_{n, i}$ refers to the rated apparent power of a single wind turbine; $N_{w t}$ refers to the number of wind turbines connected to the common connection point.

b. Switch operation

The total flicker caused by the switching operation of multiple units in the wind farm can be calculated by equations (8) and (9):

$$
\begin{aligned}
& P_{s t}=\frac{18}{S_{k}} \cdot\left(\sum_{i=1}^{N_{w t}} N_{10, i}\left(k_{f, i}\left(\psi_{k}\right) \cdot S_{n, i}\right)^{3.2}\right)^{0.31} \\
& P_{l t}=\frac{8}{S_{k}} \cdot\left(\sum_{i=1}^{N_{w t}} N_{120, i}\left(k_{f, i}\left(\psi_{k}\right) \cdot S_{n, i}\right)^{3.2}\right)^{0.31}
\end{aligned}
$$

Among them, $N_{10, i}$ and $N_{120, i}$ refer to the number of switching operation of the wind turbine in $10 \mathrm{~min}$ and $120 \mathrm{~min}$ respectively; $k_{f, i}$ is the flicker step coefficient of the wind turbine; and $S_{n, i}$ is the rated power of the wind turbine.

c. Flicker transmission

According to GB12326-2000 Voltage Fluctuation and Flicker, the transmission of flicker on different bus nodes of the power system can be simplified and calculated according to equation (10):

$$
P_{s t A}=T_{B A} P_{s t B}
$$

$P_{s t A}$ is the flicker value at node $A$ when the flicker value of node $B$ is transferred to node $A ; P_{s t B}$ is the flicker value at node $B ; T_{B A}$ is the transfer coefficient of node $B$ 's short-term flicker value transfer to node $A$, which can be calculated by the following formula (11).

$$
T_{B A}=\frac{S_{s c A}^{\prime}}{S_{s c A}-S_{s c B}^{\prime}}
$$

$S_{s c A}$ is the short-circuit capacity of node $A, S_{s c A}^{\prime}$ is the short-circuit capacity of node $A$ flowing to node $\mathrm{B}$ when node $B$ is short-circuited, $S_{s c B}^{\prime}$ is the short-circuit capacity of node $B$ flowing to node $A$ when node $A$ is short-circuited.

\subsubsection{Voltage harmonics caused by decentralized wind power}

(1) Causes of voltage harmonics

Harmonics in the power system are caused by the presence of non-linear devices such as ferromagnetic saturation equipment, electronic switching equipment, and arc equipment. For wind turbines, the harmonics generated by the generator itself are negligible, and the real source of harmonic currents is the power electronic components used in the wind turbines. No matter what type of variable speed wind turbine, the inverter will 
always be in working condition after the unit is put into operation $^{[10]}$

\section{(2) Calculation of harmonics}

a. Harmonic current allowable value

The national standard GB/T14549-93 gives the reference short-circuit capacity and the allowable value of the harmonic current at the harmonic current injection point under each voltage level.

When the minimum short-circuit capacity at the common connection point is different from the reference short-circuit capacity, the conversion of the harmonic current is shown in the formula:

$$
I_{h}=\frac{S_{k 1}}{S_{k 2}} I_{h p}
$$

In the formula (12), $S_{k 1}$ is the minimum short-circuit capacity of the common connection point, $S_{k 2}$ is the reference short-circuit capacity, $I_{\mathrm{hp}}$ is the allowable value specified by the national standard, and $I_{\mathrm{h}}$ is the allowable value when the short-circuit capacity is $S_{k 1}$.

b. Calculation of the harmonic current of multiple wind turbines connected to the common connection point

According to the calculation method of the total harmonic current distortion given in IEC61000-3-6, IEC61000-21 gives the calculation formula of the harmonic current caused by multiple wind turbines connected to the common connection point:

$$
I_{h \Sigma}=\beta \sqrt{\sum_{i=1}^{N_{w t}}\left(\frac{I_{h, i}}{n_{i}}\right)^{\beta}}
$$

In the formula, $I_{h \Sigma}$ is the harmonic current distortion on the common connection point; $N_{w t}$ is the number of wind turbines connected to the common connection point; $n_{i}$ is the transformation ratio of the wind turbine transformer, $I_{h, i}$ is the harmonic current distortion of the wind turbine.

\subsection{The influence of decentralized wind power on distribution network power flow}

Common distribution network load distribution can be divided into three types: uniform distribution along the feeder, increasing distribution and decreasing distribution. Three kinds of load distribution are deduced separately and the simulation calculation is carried out, and it can be known that ${ }^{[11]}$ :

(1) Distributed wind power access to the grid will increase the voltage of the access point, and the first point where the voltage exceeds the limit must be the access node. Appropriate and reasonable access to wind power can reduce the loss of the distribution network and improve the voltage level.

(2) By comparing and analyzing the changes in the distribution network loss when wind power is connected to different locations, it can be found that the on-site wind power consumption can effectively reduce the network loss and improve the economic efficiency of grid operation.

(3) In the actual power grid, the optimized configuration of multi-point access for multiple voltage levels should be combined with the load distribution of each voltage level and the distribution characteristics of the wind farm.

\subsection{The impact of decentralized wind power on distribution network relay protection}

(1) Impact on the scope of protection. Distributed wind power changes the sensitivity of the line protection, which may cause protection failure or malfunction. Whether it is connected to the bus or line, it will affect the fault current flowing through the upstream and downstream protection of the access point. Compared with non-connected wind power, the fault current flowing through the downstream protection of the wind power access point increases, while the fault current flowing through the upstream protection decreases. This will increase the downstream protection action range, which may cause leapfrog action and loss of coordination; while the upstream protection action range will become smaller, and its protection range may not reach the full line.

(2) Destruction of the protection direction. When the adjacent line fails, the distributed wind power will cause the protection of the line to malfunction. The traditional distribution network is a single-sided power supply, so the relay protection has no directional components. After the decentralized wind power is connected, most of the distribution network becomes a multi-terminal power supply network. Therefore, when the upstream line of wind power fails, the direction of the fault current provided by the wind power flows from the load side to the system side. For upstream protection devices that are not equipped with directional components, once the fault current exceeds the set value, the protection will act and lose its selectivity.

(3) The influence of the access position on the relay protection. When connected to the bus, the boosting characteristics of the distributed wind power will increase the fault current, thereby expanding the protection range, which may extend to the next level of lines and cause a leapfrog operation, making the protection lose selectivity. When connected to the line, it will support the voltage of the access point, so that the fault current flowing through the protection installation will be reduced. This shunting effect will reduce the sensitivity of the protection on the upper line. When the distributed wind impedance is much smaller than the equivalent impedance of the system, the shunting effect is greater and the protection may refuse to move.

Figure 1 is taken as an example to simply analyze the impact of distributed wind power on relay protection. 


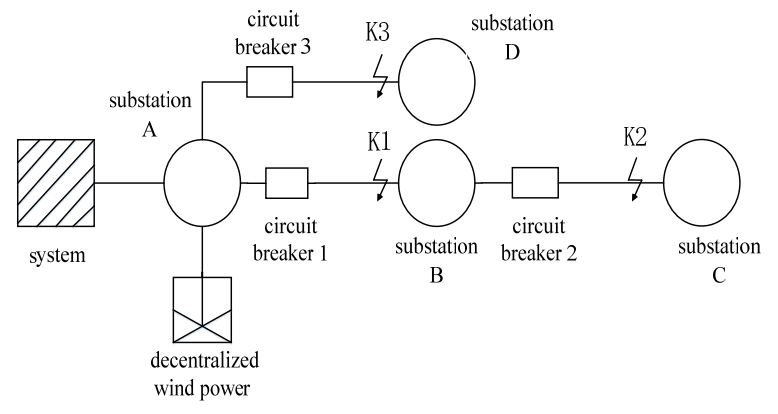

Fig. 1. The influence of decentralized wind power on relay protection

When a short-circuit fault occurs at any point $\mathrm{K} 1$ on the line between substation $A$ and $B$, the current felt by the protection of the faulted line is provided by the system and wind power together. This effect is beneficial and makes the original protection more sensitive.

When a short-circuit fault occurs at any point $\mathrm{K} 2$ on the line between the substation $B$ and $C$, the circuit breaker 2 should be used to remove the faulty line. But when the capacity of wind power is large enough, the protection range of circuit breaker 1 may extend to the line between substation $B$ and $C$, and both protections will operate, and the relay protection will lose its selectivity.

\subsection{The impact of decentralized wind power on grid planning}

The integration of decentralized wind power will make the load forecasting, planning and operation of the power grid more uncertain. A large number of distribution network users install distributed wind power to obtain electric energy, making it more difficult for distribution network planners to accurately predict load growth, which affects planning ${ }^{[12,13]}$.

In order to maintain the safe and stable operation of the system, the distributed wind power must be able to accept real-time dispatch. To achieve this goal, it is not only necessary to improve the existing distribution automation system, but also to manage the grid from passive to active.

\section{Conclusion and prospect}

\subsection{Conclusion}

Decentralized wind power is a new development model proposed in response to the grid situation, which is of great significance for improving the utilization of wind energy. Distributed wind power is connected to the distribution network, which can reduce network loss and improve voltage. With the development of technology, there is an urgent need to establish corresponding technical standards and incentive policies for decentralized wind power integration to lay the foundation for the rapid and healthy development of decentralized wind power.

\subsection{Prospect}

At present, domestic research on decentralized wind power is still in its infancy. This article mainly elaborates the impact of distributed wind power on the distribution network, but it should be combined with specific examples to build a model for in-depth analysis.

\section{References}

1. G.H Xie, Y.S He, Q.G Wang. Research on development prospect of wind power in eastern and central China[J]. Electric Power, 2018, 51(3): 100104.

2. Huang B.B, Zhang Y.Z, Wang C.X. New energy development and issues in China during the 14th Five-Year Plan[J]. Electric Power, 2020, 53(1): 1-9.

3. Z.Q Wang, S.Z Zhu, S.X Zhou, et al. Impacts of distributed generation on distribution system voltage profile $[\mathrm{J}]$. Automation of Electric Power Systems, 2004, 28(16): 56-60.

4. D.X Zhang, X.H Xu, L Yang, et al. The impact of distributed generators on distribution network overvoltage $[\mathrm{J}]$. Automation of Electric Power Systems, 2007, 31(12): 50-54, 85.

5. Y.Q Lian, Z.Y Yuan, J.Y Lei, X.Y Ma, S.Y Tao. Impact of Dispersed Wind Farm Integration on Distributed Network in Different Scenarios[J]. Electric Power,2020,53(04):49-58.

6. H Peng, S.F Li, Y.J Li, Y.Y Li, J Ding, et al. Study on influence of decentralized wind power on voltage fluctuation of regional distribution network[J]. Electrotechnical Application, 2014, 33 (13): 18-22.

7. X.Y Wang. Decentralized wind power generation to reduce the loss of distribution network of a preliminary study[J]. Electric Age, 2011 (5): 80-82.

8. H.X Zhao, M.Z Chen, H.Z Dai.Testing system simulation of flicker caused by grid-connected wind power[J]. Acta Solara Sinica, 2005,26 (1): 28-33.

9. H.B Bai, R.H Wang, Z Wang, Y.N Chi. Analysis Method of Power Quality with the Integration of Wind Power and Case Study[J]. Journal of Northeast Dianli University Natural Science Edition, 2008, 28(06): 33-37.

10. W.Z Gandhare, G.R Bhagwatikar. Power pollution due to connected wind electric converter[J]. Proceedings of the 2000 IEEE international conference on control applications, Anchorage, Alaska, USA, September 25-27, 2000.

11. M Wang, M Ding. Planning of distribution network system with distributed power supply[J]. Rural Electrification, 2003 (7): 19-20.

12. J Wang, X.Y Li, X.Y Qiu. A review of power systems with distributed generation[J]. Automation of Electric Power Systems, 2005,29 (24): 90-97.

13. H.Y Chen, J.F Chen, X.Z Duan. Power flow calculation of distribution network with distributed 
power supply[J]. Automation of Electric Power Systems, 2006,30 (1): 35-40. 